\title{
Antibiotics Resistance of Vibrio spp. Isolated from Diseased Seabass and Tilapia in Cage Culture
}

\author{
Hamdan $\mathrm{RH}^{1}$, Peng $\mathrm{TL}^{1}$, Ong BL ${ }^{1}$, Suhana MYS ${ }^{1}, \mathrm{Hamid}_{\mathrm{NH}}^{2}$, Afifah $\mathrm{MNF}^{2}$, Raina $\mathrm{MS}^{3}$ \\ ${ }^{1}$ Faculty of Veterinary Medicine, University Malaysia Kelantan \\ Locked Bag 36, Pengkalan Chepa, 16100 Kota Bharu, Kelantan, Malaysia \\ ${ }^{2}$ Faculty of Veterinary Medicine, Universiti Putra Malaysia, 43400 Serdang, Selangor, Malaysia \\ ${ }^{3}$ Faculty of Plantation \& Agrotechnology, University Technology Mara (Melaka) \\ Jasin Campus, Merlimau, Melaka, Malaysia \\ ruhil@umk.edu.my
}

\begin{abstract}
Vibriosis has become one of the most important bacterial diseases in marine cultured organisms in recent years. This study was focusing on isolation and identification of Vibrio spp. isolated from diseased seabass (Lates calcarifer), tilapia (Oreochromis niloticus) and seawater from Sri Tujuh lagoon in East Coast of Malaysia; also determination of antibiotic resistance patterns among Vibrio spp. Vibrio species isolated from diseased seabass in Pantai Sri Tujuh, Tumpat, Kelantan were screened for their antibiotic sensitivity patterns by Kirby-Bauer method. A total of 47 isolates belonging to three different species were identified which are $V$. parahaemolyticus, $V$. vulnificus, and $V$. alginolyticus. In this study, high incidence of erythromycin, chloramphenicol and sulfamethoxazole resistance was observed among the Vibrio isolates, whereas all isolates were susceptible to oxytetracycline. Vibrio isolates were $96 \%$ resistant to one or more different classes of antibiotic, and 17 different resistance patterns were identified. The MAR index of 0.4 indicating the Vibrio spp. in these farmed fish might have been indiscriminately and continuously exposed to those antibiotics during culturing stages of the fish. This study showed that multidrug-resistant Vibrio spp. were common in diseased seabass and tilapia cultured at Sri Tujuh lagoon. These essential findings suggested involvement of seafood in transmission of these pathogen to human. In addition, oxytetracycline can be used as a treatment to combat vibriosis in diseased seabass and tilapia.
\end{abstract}

Key Words:Vibrio spp., Lates calcarifer, Oreochromis niloticus, Antibiotic Resistance

\section{INTRODUCTION}

Vibrios are ubiquitous in aquatic environments, depending on their salt requirement for optimum growth. However, clinical disease outbreaks only occur when a stressed fish get exposed to infectious agent (Abdel-Aziz et al. 2013). Vibriosis affects aquaculture of many commercially important species elsewhere, which include penaeid shrimp (Ransangan et al. 2013), gilthead sea bream (Abdel-Aziz et al. 2013), European seabass (Abdel-Aziz et al. 2013), tiger puffer (Mohi et al. 2013), groupers (Anand et al. 2008; Mienda 2012), flounder (Kim et al. 2014) and Asian seabass (Ransangan et al. 2011). You et al. (2016) stated that genus Vibrio encompases more than 63 species, whereas one third are potential human pathogens and have been implicated in water- and seafood-related outbreaks of gastrointestinal and wound infections in humans. Vibrio vulnificus, V. haryei, $V$. parahaemolyticus, $V$. alginolyticus, and $V$. mimicus are the common aetiology of vibriosis in marine aquaculture industry that have been reported to cause mortality and severe economic losses (You et al. 2016). Bondad-Reantaso et al. (2005) stated that Malaysia losses US\$ 7.4 million to vibriosis in 1990. Multiple antibiotic resistance (MAR) was defined as resistance to two or more antibiotics (Shaw et al. 2014). Antibiotics have been widely used to treat vibriosis in humans and aquaculture livestock. The use of antibiotics in various clinical applications and aquaculture resulted in emerging of 
antibiotic-resistant bacteria. Hence, reduces the effectiveness of antibiotic to combat both human and animal infections (Malla et al. 2014). In this study, evaluation of antibiotic resistance patterns of Vibrio spp. was done which were isolated from diseased seabass and tilapia; and water systems at Sri Tujuh lagoon, Tumpat, Kelantan, Malaysia

\section{MATERIAL AND METHODS}

\section{Bacterial isolation and identification}

Diseased seabass and tilapia showed clinical signs of exophthalmia, emaciation, skin darkening and body ulceration were collected from Sri Tujuh Lagoon. Loopful of kidney, spleen and external lesion of the fish were streaked separately onto thiosulfatecitrate-bile salts-sucrose (TCBS, Oxoid, England). For seawater, $0.1 \mathrm{ml}$ of sample were spread plated onto TCBS. The inoculated plates were incubated at $30^{\circ} \mathrm{C}$ overnight. The selected colonies were identified using Gram staining, oxidase, catalase and API 20E (Biomerieux, France).

\section{Antibiotic sensitivity tests}

The Kirby-Bauer method was used to determine the antibiotic sensitivity patterns of isolates. The resistance of all strains to different antimicrobial agents was determined by the disc diffusion method. The pellet was inoculated onto $0.85 \%$ saline and compared to 0.5 McFarland Equivalence Turbidity Standard (Remel USA). The entire Mueller Hinton (MH, Oxoid, England) agar surface was streaked horizontally, vertically and around the outer edge of the plate by sterile swab. An antibiotic loaded paper disc was put onto $\mathrm{MH}$ agar. Antibiotics used were ampicillin $(10 \mu \mathrm{g})$, erythromycin $(15 \mu \mathrm{g})$, gentamicin $(10 \mu \mathrm{g})$, oxytetracycline $(30 \mu \mathrm{g})$, sulfamethoxazole $(25 \mu \mathrm{g})$, and chloramphenicol $(30 \mu \mathrm{g})$ (Oxoid, England). All cultures plates were incubated for $24 \mathrm{~h}$ at $30^{\circ} \mathrm{C}$. The results of inhibition zones were interpreted as sensitive (S), intermediary sensitive (I), and resistance (R) according to the reference to the standard provided by the National Committee for Clinical Laboratory Standards (CLSI 2015).

\section{Multiple antibiotic resistance (MAR) index}

Multiple antibiotic resistance (MAR) index of present isolates against the tested antibiotics was calculated based on the following formula (Krumperman 1983):

MAR index $=\mathrm{X} /(\mathrm{Y} \times \mathrm{Z})$

Where, $\mathrm{X}=$ Total cases of antibiotic resistance; $\mathrm{Y}=$ Total number of antibiotic used in the study; $\mathrm{Z}=$ Total number of isolates. A MAR index value of equal or less than 0.2 was defined as antibiotics that were seldom or never used.

\section{RESULTS AND DISCUSSION}

In the present study, we found that $V$. parahaemolyticus and $V$. alginolyticus were the predominant isolates from diseased seabass and tilapia (Table 1). You et al. (2016) stated that both species are commonly detected in tropical marine regions. Those species also are among the most important disease causing agents of many commercially farmed marine invertebrate and vertebrate species in many Asian countries. Moreover, V. vulnificus also was isolated from seawater in Sri Tujuh lagoon. This pathogenic species in coastal, estuary, and river waters may pose a significant health hazard to local individuals who 
have direct contact with water through recreational activities or via seafood consumption (You et al. 2016). Table 2 showed biochemical tests results for $V$. parahaemolyticus, $V$. alginolyticus and $V$. vulnificus isolated from diseased seabass, tilapia and seawater. The results obtained in this study was in accordance with several reports which using API 20E kit (Biomerieux) as identification tool to characterize the isolates of $V$. parahaemolyticus, $V$. alginolyticus and V. vulnificus (Biosca et al. 1996; Martinez-Urtaza et al. 2006; Martins et al. 2010).

Table 1. Vibrio spp. isolated from diseased seabass and tilapia

\begin{tabular}{lll}
\hline \hline Strain ID & \multicolumn{1}{c}{ Spesies } & \multicolumn{1}{c}{ Source } \\
\hline VP1 & V.parahaemolyticus & Seawater \\
VP2, VP3, VP4, VP5, VP6, & V.parahaemolyticus & Kidney of seabass \\
VP7, VP8, VP9, VP10, VP11, & & \\
VP12, VP13, VP14, VP15, & & \\
VP16, VP17, VP18, VP19, & & \\
VP20, VP21, VP22, VP23, & & \\
VP24, VP25, VP26, VP27, & V. alginolyticus & \\
VP28, VP29, VP30 & & Kidney of tilapia \\
VA1, VA3, VA4, VA5, VA6, & Seawater \\
VA7, VA10, VA12, VA13, & & \\
VA14, VA16, & V. alginolyticus \\
VA2, VA8, VA9, VA11, VA15 & V. vulnificus & \\
VV1 & & \\
\hline
\end{tabular}

The frequencies of resistance were observed against erythromycin (85\%), chloramphenicol (58\%), sulfamethoxazole (49\%) ampicillin (32\%), and gentamycin (11\%). You et al. (2016) stated that the resistance of Gram-negative bacteria to erythromycin is expected due to their intrinsic resistance. Ampicillin has been widely used since 1960 and ampicillin resistance is also commonly reported (Laganà et al. 2011, You et al. 2016). Common drugs used in agriculture, livestock operations, aquaculture, and human therapy are Sulfonamides (sulfa drugs) (Suzuki et al. 2013). This class of antibiotics are widely use all over the world especially in developing Asian countries as a result of their inexpensiveness and wide spectrum antimicrobial activity (Luo et al. 2011; Suzuki \& Hoa 2012). Resistance to sulfonamides has been reported in clinical, aquaculture, and aquatic environments from different geographical regions (Hoa et al. 2008, 2011; You et al. 2012; Suzuki et al. 2013; Das et al. 2014). Pantai Sri Tujuh lagoon is adjacent to irrigation, a site where there have been numerous wastewater treatment overflows. Consequently, inputs from domestic sewage might be a cause of notable frequency of sulfonamide-resistant bacteria detected in diseased seabass and tilapia. In other hand, all the Vibrio isolates were found to be susceptible to oxytetracycline. This findings were in agreement with study done by You et al. (2016) which showed the sensitivity of oxytetracycline against Vibrio spp. isolated from waters in Peninsular Malaysia.

The resistance patterns of all the 47 Vibrio isolates are shown in Table 3. Multiple antibiotic resistance was observed and 17 different resistance patterns were identified among the isolates. In this study, $96 \%$ of Vibrio isolates were resistant to one or more different classes of antibiotic. None of the isolates susceptible to all antibiotics tested, indicating widespread occurrence of MAR Vibrio spp. in diseased seabass and tilapia. One $V$. vulnificus strain isolated from seawater found to be resistant to five different classes of 
antibiotic. Our results showed that Vibrio isolates showed high frequency of MAR (80\%). The MAR index of 0.4 indicating the Vibrio spp. in these farmed fish might have been indiscriminately and continuously exposed to those antibiotics during culturing stages of the fish. There were no clear species-specific antibiotic resistance patterns in this study. The current results are in agreement with others studies showing multiresistance incidence in Vibrio spp. from aquatic environments and seafood samples (Baker-Austin et al. 2009; Zulkifli et al. 2009; Lesley et al. 2011; Noorlis et al. 2011; You et al. 2016.).

Table 2. Biochemical tests results for $V$. parahaemolyticus, $V$. alginolyticus and V. vulnificus isolated from diseased seabass, tilapia and seawater

\begin{tabular}{lccc}
\hline \hline Biochemical tests & V. parahaemolyticus & V. alginolyticus & V. vulnificus \\
\hline ONPG & - & - & + \\
ADH & - & - & - \\
LDC & + & + & + \\
ODC & + & + & + \\
CIT & - & + & - \\
H 2 S & - & - & - \\
URE & - & - & - \\
TDA & - & + & - \\
IND & + & + & + \\
VP & - & - & - \\
GEL & - & + & + \\
GLU & + & + & + \\
MAN & + & + & - \\
INO & - & - & - \\
SOR & - & - & - \\
RHA & - & - & - \\
SAC & - & - & - \\
AMY & V & + & + \\
ARA & - & + & - \\
OX & + & + & + \\
CAT & + & + \\
\hline
\end{tabular}

+: Positive reaction; -: Negative reaction; V: Variable; ONPG: $\beta$-galactosidase; ADH: Arginine dihydrolase; LDC: Lysine decarboxylase; ODC: Ornithine decarboxylase; CIT: Citrate; $\mathrm{H}_{2} \mathrm{~S}$ : Hydrogen sulfide; URE: Enzyme urease; TDA: Tryptophane deaminase; VP: Vogesproskauer; IND: Indole; GEL: Gelatine; GLU: Glucose; MAN: Mannitol; INO: Inositol; SOR: Sorbitol; RHA: Rhamnose; SAC: Saccharose; AMY: Amygdalin; ARA: Arabinose; OX: Oxidase; CAT: Catalase 
Table 3. The antibiotic resistance profile patterns of Vibrio spp. from seabass, tilapia and seawater

\begin{tabular}{lcc}
\hline \hline Pattern & Strain number & Antibiotic profiles \\
\hline I & VP1 & CN, E \\
II & VA1, VP6, VP13, VP21, VP28 & AMP, C, SXT, E \\
III & VP3, VP9, VP10, VP11, VP14, VP16, & C, SXT, E \\
IV & VA9, VP18, VP23, VP27, VA16 & \\
V & VP5, VA7 & AMP, C, E \\
VI & VA3, VP20 & SXT, E \\
VII & VA5 & C, SXT, CN, E \\
VIII & VA8 & AMP, SXT, E \\
IX & VV1 & AMP, C, SXT, CN, E \\
X & VA12, VA14 & AMP, E \\
XI & VP26 & AMP, C \\
XII & VA13 & AMP, C, CN, E \\
XIII & VA15 & AMP, SXT \\
XIV & VP19, VA10, VP24, VP25 & C, E \\
XV & VP22, VP29, VP30 & E \\
XVI & VA2 & \\
XVII & VA6 & AMP \\
\hline
\end{tabular}

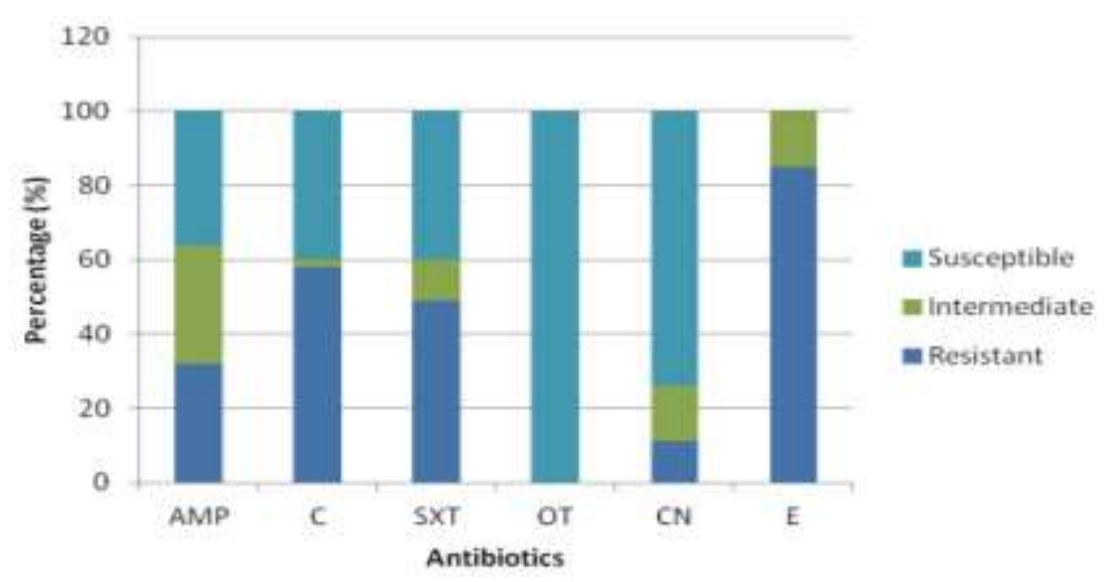

AMP: Ampicillin; C: Chloramphenicol; SXT: Sulfamethoxazole; OT: Oxytetracycline; $\mathrm{CN}$ : Gentamicin; E: Erythromycin

Figure 1. Antibiotic susceptibility of Vibrio spp. isolated from seabass, tilapia and seawater

\section{CONCLUSION}

This study revealed that the antibiotic-resistant and multidrug-resistant Vibrio spp. were common in seabass, tilapia and seawater of Sri Tujuh lagoon, East Coast Malaysia. The findings implying a great risk to public health. Constant surveillance and monitoring of antibiotic resistance and pollution levels of antibiotics should be done in order to compile more information on antibiotic sensitivity of Vibrio spp. and other known aquatic bacteria species in order to avoid the development of antibiotic superbug. Likewise, the increase of antibiotics resistant Vibrio spp. will lead to treatment challenge in vibriosis. 


\section{ACKNOWLEDGEMENT}

The authors would like to express their gratitude to Faculty of Veterinary Medicine, University Malaysia Kelantan; Knowledge Transfer Programme (KTP), Malaysian Higher Education and Sri Tujuh Lagoon Community.

\section{REFERENCES}

Abdel-Aziz M, Eissa AE, Hanna M, Okada MA. 2013. Identifying some pathogenic Vibrio or Photobacterium species during mass mortalities of cultured Gilthead seabream (Sparus aurata) and European seabass (Dicentrarchus labrax) from some Egyptian coastal Provinces. Int J Vet Sci Med. 1:87-95.

Baker-Austin C, McArthur JV, Lindell AH, Wright MS, Tuckfield RC, Gooch J, Warner L, Oliver J, Stepanauskas R. 2009. Multi-site analysis reveals widespread antibiotic resistance in the marine pathogen Vibrio vulnificus. Microbial Ecol. 57:151-159.

Biosca EG, Oliver JD, Amaro C. 1996. Phenotypic characterization of Vibrio vulnificus biotype 2, a lipopolysaccharide-based homogeneous o serogroup within Vibrio vulnificus. Appl Env Microb. 62:918-927.

Bondad-Reantaso MG, Subasinghe RP, Arthur JR, Ogawa K, Chinabut S, Adlard R, Tan Z, Shariff M. 2005. Disease and health management in Asian aquaculture. Vet Parasitol. 32:249-272.

CLSI. 2015. Performance standards for antimicrobial susceptibility testing; M100-S25. Wayne (USA): Clinical and Laboratory Standards Institute.

Das SK, Rahman A, Chisti MJ, Ahmed S, Malek MA, Salam MA, Bardhan PK, Faruque ASG. 2014. Changing patient population in Dhaka Hospital and Matlab Hospital of ICDDR, b. Trop Med Int Health. 19:240-243.

Hoa PTP, Nonaka L, Viet PH, Suzuki S. 2008. Detection of the sul1, sul2, and sul3 genes in sulfonamideresistant bacteria from wastewater and shrimp ponds of North Vietnam. Sci Total Environ. 405:377-384.

Hoa PHP, Managaki S, Nakada N, Takada H, Shimizu A, Anh DH, Viet PH, Suzuki S. 2011. Antibiotic contamination and antibiotic-resistant bacteria in animal farms, city canal and aquaculture environments of North Vietnam. Sci Total Environ. 409: 2894-2901.

Kim MS, Cho JY, Choi HS. 2014. Identification of Vibrio harveyi, Vibrio ichthyoenteri, and Photobacterium damselae isolated from olive flounder Paralichthys olivaceus in Korea by multiplex PCR developed using the rpoB gene. Fish Sci. 80:333-339

Krumperman PH. 1983. Multiple antibiotic resistance indexing of Escherichia coli to identify high-risk sources of fecal contamination of foods. Appl Environ Microbiol. 46:165-170.

Laganà P, Caruso G, Minutoli E, Zaccone R, Delia S. 2011. Susceptibility to antibiotics of Vibrio spp. and Photobacterium damsela spp. piscicida strains isolated from Italian aquaculture farms. New Microbiol. 34:53-63.

Lesley MB, Velnetti L, Cheah YK, Son R, Kasing A, Samuel L, Micky V, Nishibuchi M. 2011. Antibiotic resistance and plasmid profiling of Vibrio parahaemolyticus isolated from cockles (Anadara granosa) at Tanjung Karang, Kuala Selangor. Int Food Res J. 18:1183-1188.

Luo Y, Xu L, Rysz M,Wang Y, Zhang H, Alvarez PJJ. 2011. Occurrence and transport of tetracycline, sulfonamide, quinolone, and macrolide antibiotics in the Haihe River Basin, China. Environ Sci Technol. 45:1827-1833.

Malla S, Dumre SP, Shakya G, Kansakar P, Rai B, Hossain A, Nair GB, Albert MJ, Sack D, Baker S, Rahman M. 2014. The challenges and successes of implementing a sustainable antimicrobial resistance surveillance programme in Nepal. BMC Public Health. 14:269-275. 
Martinez-Urtaza J, Lozano-Leon A, Vina-Feas A, de Novoa J, Garcia-Martin O. 2006. Differences in the API 20E biochemical patterns of clinical and environmental Vibrio parahaemolyticus isolates . FEMS Microbiol. Lett. 255:75-81.

Martins ML, Mouriño JLP, Fezer GF, Buglione Neto CC, Garcia P, Silva BC, Jatobá, Vieira, FN. 2010. Isolation and experimental infection with Vibrio alginolyticus in the sea horse, Hippocampus reidi Ginsburg, 1933 (Osteichthyes: Syngnathidae) in Brazil. Braz. J Biol. 70:205-209.

Mienda BS. 2012. Proteolytic activity of Vibrio parahaemolyticus isolated from Epinephilus spp. A Preliminary Report. Res Biotechnol. 3:36-40.

Mohi MM, Kuratani M, Miyazaki T, Yoshida T. 2010 Histopathological studies on Vibrio harveyi - Infected tiger puffer, Takifugu rubripes (Temminck et Schlegel), cultured in Japan. J Fish Dis. 33:833-840.

Noorlis A, Ghazali FM, Cheah YK, Tuan Zainazor TC, Wong WC, Tunung R, Nishibuchi M, Nakaguchi Y, Son R, Pui CF. 2011. Antibiotic resistance and biosafety of Vibrio cholera and Vibrio parahaemolyticus from freshwater fish at retail level. Int Food Res J. 18:59-66.

Ransangan J, Mustafa S. 2009. Identification of Vibrio harveyi isolated from diseased Asian seabass Lates calcarifer by use of $16 \mathrm{~S}$ ribosomal DNA sequencing. J Aquatic Anim Health. 21:150-155.

Ransangan J, Imm LKL, Tamrin ML, Sade A. 2013. Phenotypic characterization and antibiotic susceptibility of Vibrio spp. isolated from aquaculture waters on the west coast of Sabah, Malaysia. Int J Res Pure Appl Microbiol. 3:58-66.

Shaw KS, Rosenberg Goldstein RE, He X, Jacobs JM, Crump BC, Sapkota AR. 2014. Antimicrobial susceptibility of Vibrio vulnificus and Vibrio parahaemolyticus recovered from recreational and commercial areas of Chesapeake Bay and Maryland coastal bays. PLoSOne 9:e89616.

Shyne Anand PS, Sobhana KS, George KC, Paulraj R. 2008. Phenotypic characteristics and antibiotic sensitivity of Vibrio parahaemolyticus strains isolated from diseased groupers (Epinephelus spp.). J Marine Biol Assoc India. 50:1-6.

Suzuki S, Hoa PTP. 2012. Distribution of quinolone, sulfonamides, tetracyclines in aquatic environment and antibiotic resistance in Indochina. Front Microbiol. 3:1-8.

Suzuki S, Ogo M, Miller TW, Shimizu A, Takada H, Siringan MA. 2013. Who possesses drug resistance genes in the aquatic environment? Sulfamethoxazole (SMX) resistance genes among the bacterial community in water environment of Metro-Manila, Philippines. Front Microbiol. 4:1-12.

You KG, Bong CW, Lee CW. 2012. Antimicrobial resistance in bacteria isolated from tropical coastal waters of Peninsular Malaysia. Malaysian J Sci. 31:111-120.

You KG, Bong CW, Lee CW. 2016. Antibiotic resistance and plasmid profiling of Vibrio spp. in tropical waters of Peninsular Malaysia. Environ. Monit Assess. 188:171.

Zulkifli Y, Alitheen NB, Raha AR, Yeap SK, Marlina SR, Nishibuchi M. 2009. Antibiotic resistance and plasmid profiling of Vibrio parahaemolyticus isolated from cockles in Padang, Indonesia. Int Food Res J. 16:53-58. 